\title{
Transient Stability of Fault Ride Through Capability of a Transmission System of a Distributed Hydropower System
}

\author{
J. Manjula Edirisinghe V.P. ${ }^{1} \quad{\text { Thomas } \text { Øyvang }^{1} \quad \text { Gunne John Hegglid }}^{1}$ \\ ${ }^{1}$ Faculty of Technology, Natural Sciences and Maritime Sciences, University College of Southeast Norway, Post box 235, \\ N-3603 Kongsberg, Norway, \{jagathe.m.edirisinghe, Thomas.Oyvang, gunne.j.hegglid\}@usn.no
}

\begin{abstract}
This paper describes the Fault Ride Through (FRT) capability of generators of a part of the $132 \mathrm{kV}$ high voltage power network in Telemark region, Norway using a simplified power system simulator model. The organization, "European network of transmission system operators for electricity" (ENTSO-e) is introducing a network code for the Transmission System Operators (TSO) in Europe where the upper limit of the FRT requirement for $132 \mathrm{kV}$ system is $0.25 \mathrm{~s}$. However, according to the Norwegian network code, this limit is $0.40 \mathrm{~s}$. The generators in the Norwegian power system are located in a distributed network and most of these are hydropower generators. The simulation results show that the structure of the Nordic power system enhances the system stability. The dynamic model of the power network is developed by using DIgSILENT PowerFactory simulation tool.
\end{abstract}

Keywords: $\quad$ power system, transient stability, Fault Ride Through capability, hydropower, simulations, DIgSILENT

\section{Introduction}

The electric power system is one of the complex man made networks, which is subjected to frequent improvements and changes. Power market today is more international and transmission system operators (TSO) in Europe operate in a connected power network (Statnett, 2017; ENTSO-e, 2017). Large introduction of renewable energy generations to systems such as wind power, has made the power network more complex (Delfanti et al, 2014; Gebremedhin et al, 2012; Bekele et al, 2012). TSOs have their own regulations and procedures. Therefore, the "ENTSO-e" is introducing a network code in order to harmonize the operating procedures among different TSOs and it is going to be a common network code in Europe. FRT capability of generators is one of the major consideration in harmonized power transmission systems (Diez-Maroto et al, 2016). For a generator, FRT capability is define as the ability of the generator to remain connected to the grid in the event of an external fault as long as the voltage at the connection point remains above a defined voltage level (Diez-Maroto et al, 2016).
ENTSO-e states that the synchronous generators need to stay connected if voltage at their connection point is above the voltage level defined by the FRT voltage profile. Advantage of this new code would prevent generation tripping in circuits when the fault is cleared in reasonable time. Lower time limit of the FRT requirement is set to $0.15 \mathrm{~s}$, considering the clearing time of protection relays of the first zone, on the other hand, the upper time limit is set to $0.25 \mathrm{~s}$ considering the clearing time of protection relays of the first zone and the circuit breaker failure (ENTSO-e, 2017; Diez-Maroto et al, 2016).

The Norwegian transmission system operator, Statnett has published a network code called "FIKS", which describes the functionality of the Norwegian power transmission system (FIKS, 2012). This local network code defines the FRT limit based on $220 \mathrm{kV}$ voltage limit. FRT maximum requirement time for the network above $220 \mathrm{kV}$ is $0.15 \mathrm{~s}$, while it is $0.40 \mathrm{~s}$ for the network below $220 \mathrm{kV}$. The voltage level of regional transmission networks in Norway, which is studied in this article, is below $132 \mathrm{kV}$.

At present, the FRT requirement of the European network code is an interesting topic for the European electrical power producers and Diez-Maroto et al (2016) have investigated whether a typical round rotor turbogenerator fulfills the FRT requirement for this network code. Moreover, Delfanti et al (2014) have investigated the distributed renewable energy integration into the electrical grid. In addition to that, a preliminary study of the FRT requirements of the 132 $\mathrm{kV}$ simplified Telemark regional power network has been done by Adb (2016). There were 69 buses included in the study. In the present study, the Telemark model (Adb, 2016) is more simplified to 47 bus network and static stability of the simulator is improved.

The structure of the Norwegian power system is somewhat different from the many other countries in Europe where they use more centralized power sources (Delfanti et al, 2014). There are large numbers of hydroelectric generating units which supply electricity to the Norwegian power network (Gebremedhin et al, 2012). These generators are located throughout the country in a distributed network.

In the present study, the FRT performance of hydropower generators for a part of the $132 \mathrm{kV}$ 
transmission network in Telemark region of Norway is investigated. It also compares the simulation results with FIKS's FRT time limits. Finally, the transient stability impact on a distributed power system is discussed.

When the FRT requirements of some TSOs go far beyond than which are required by International Electrotechnical Commission (IEC) and Institute of Electrical and Electronic Engineering (IEEE) standards, the generator manufactures are facing more difficulties to fulfill the requirements (Diez-Maroto et al, 2016) .

Therefore, it is an advantage to analyze FRT capability of Norwegian power system over the new code, because the future generating stations are supposed to follow the ENTSO-e regulations.

The paper is organized as follows. Section 2 provides a brief overview of a transient stability of a power system. The simulator is described in section 3 . Selection criteria of cases for the simulations are provided in section 4. Results and discussion are provided in section 5. Finally in section 6, the conclusion is presented.

\section{Transient stability of an electric power system}

Transient stability of a power system describes the dynamic security of the system. It is a fast phenomenon where the power system operators do not have sufficient time to correct it manually (Vaahedi, 2014). Figure 1 shows the classification of power system stability.

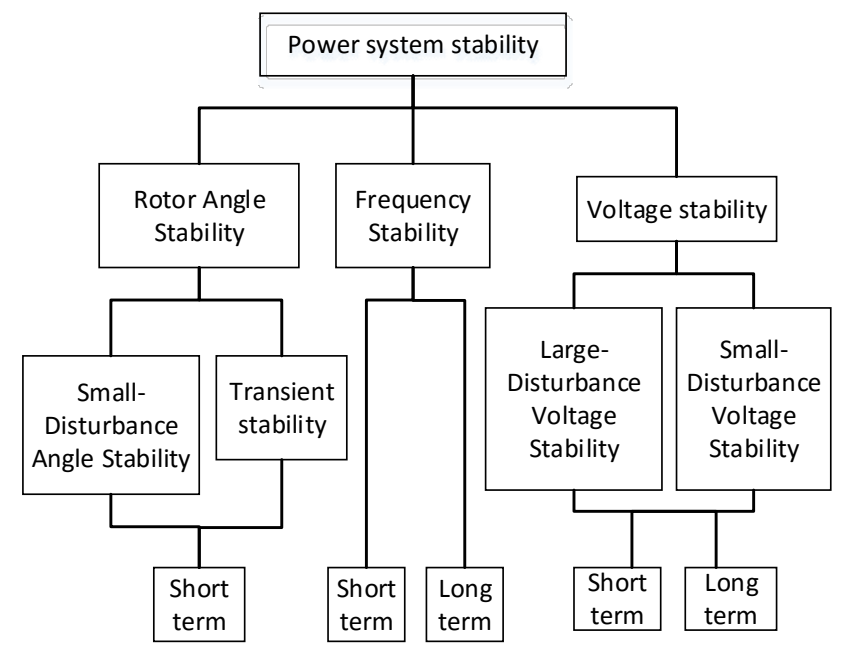

Figure 1. Classification of power system stability (Kundur et al, 2004).

According to the Figure 1, transient stability comes under the rotor angle stability. Equation (1) describes the swing equation for a generating station.

$$
\frac{d \omega}{d t}=\frac{d^{2} \delta}{d t^{2}}=\frac{\omega_{0}}{2 H}\left(P_{m}-P_{e}\right)
$$

Where, $\omega$ is the angular speed of the machine, $\delta$ is the rotor angle of the machine, $P_{m}$ is the mechanical input power to the machine, $P_{e}$ is the electrical power output of the machine, $H$ is the inertia constant of the machine in MWs / MVA, $\omega_{0}$ is the synchronous speed which is related to synchronous frequency (Vaahedi, 2014).

The various components of the acceleration torque associated with the generator rotor are described in equation (2). Here, it is assumed that the damping is represented by damping torque which is proportional to the speed deviation of the machine.

$$
T_{a}=T_{i n}-T_{e}-D_{g} \Delta \omega
$$

Where, $\mathrm{T}_{\mathrm{a}}$ is the generator accelerating torque, $T_{\text {in }}$ is the input torque, $T_{e}$ is the output torque, $D_{g}$ is the damping coefficient of the generator and $\Delta \omega$ is the speed deviation (Kundur, 1993).

The electric power output of a machine considering the single-machine infinite bus system is described in equation (3).

$$
P_{e}=\frac{E \cdot V_{\mathrm{inf}}}{X^{\prime}+X_{1}} \sin (\delta)
$$

Where, $P_{e}$ is the electric power output of the machine, $E$ is the internal voltage of the machine, $\delta$ is the phase angle induced by field voltage, $V_{\text {inf }}$ is the infinite bus voltage, $X^{\prime}$ is the internal reactance of the machine and $X_{I}$ is the reactance of the transmission line (Vaahedi, 2014).

\section{Simulator}

A simplified model of a part of the $132 \mathrm{kV}$ network in Telemark region, Norway (Adb, 2016) is simulated using a power analysis programme "Digisilent Powerfactory 2016". The overview of the simplified local power network is shown in Figure 2.

The model consists of 49 buses. The voltage levels $11 \mathrm{kV}, 22 \mathrm{kV}, 66 \mathrm{kV}, 132 \mathrm{kV}, 300 \mathrm{kV}$ and $420 \mathrm{kV}$ can be found in the model. There are 18 power generators in this model. All generators are implemented with salient pole rotors. Each and every station is equipped with an "IEEET1" automatic voltage regulator and a "HYGOV" speed governor. These two models which can be found in the software are used with standard coefficients. Buses are connected in the network using 23 transmission lines and there are 24 power transformers included in this model. T-1 2 is an auto- transformer. External grid is acting as the local power reference point (slack bus). 


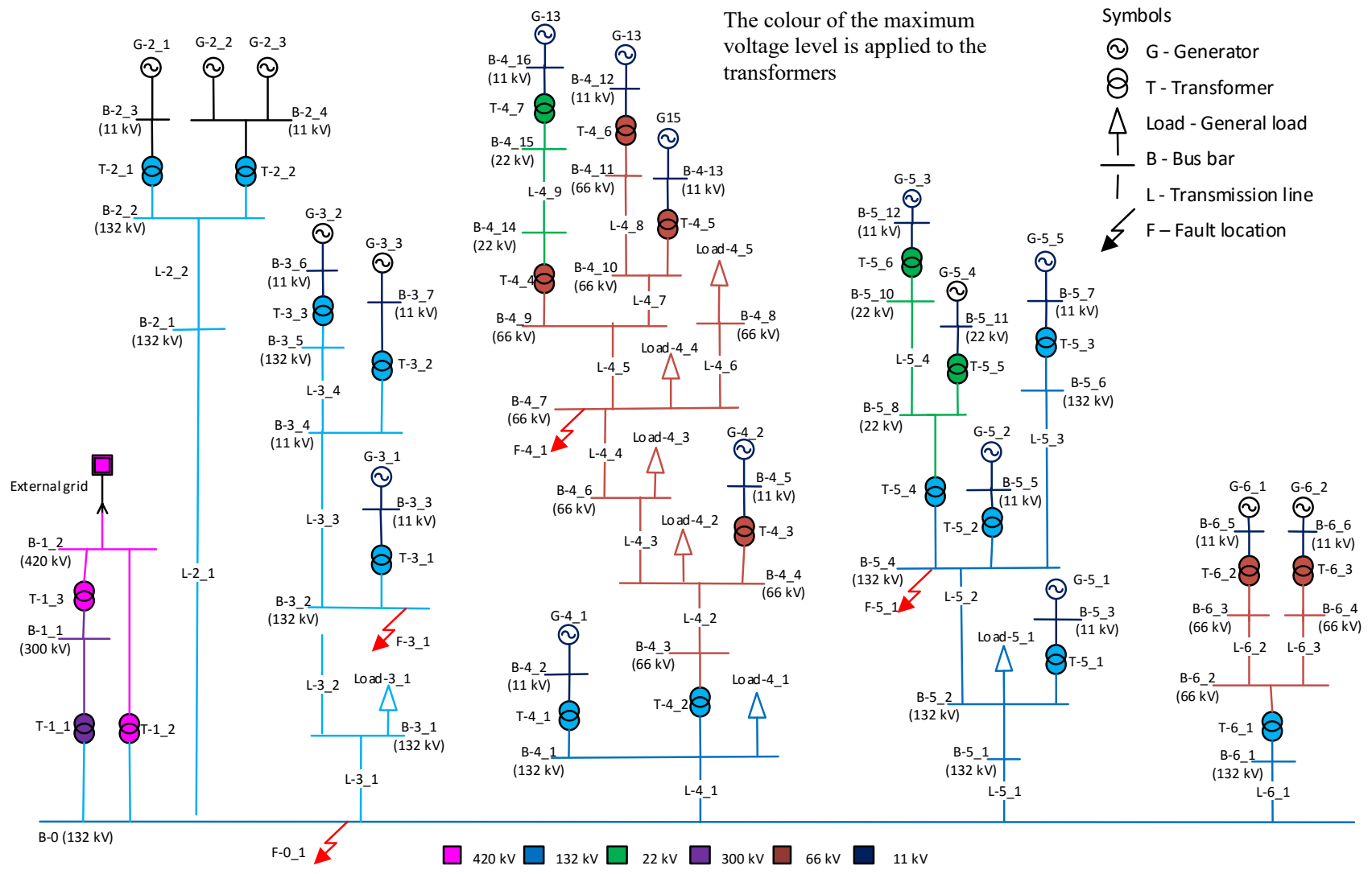

Figure 2. Simplified power system simulator for a part of $132 \mathrm{kV}$ Telemark regional power network, Norway.

First, a balanced, positive sequence AC load flow is executed using Newton-Raphson method allowing automatic adaption of step size. All the generating stations are set to their maximum power. Voltages at all the buses remain between 1 and 0.97 per unit (p.u.).

A balanced 3 phase short circuit is created using an additional transmission line. Therefore, there is no any structure change in pre-fault and post-fault network structures. Then the stability of the generators were checked by changing the fault location as shown in Figure 2. The simulations were performed for six different fault-executing times as described in Table 1.

\section{Case definition}

The considered faults are three-phase symmetrical faults. Each fault scenario was selected for different radial circuits in the Figure 2 and the main $132 \mathrm{kV}$ bus (B-0) was also selected. The manner of the voltage reduction in a fault location impacts on generating units, which are distributed with considerable impedance, was considered when the cases were selected. The selected cases are tabulated in Table 1. Each case is simulated for six different fault clearance times of $0.1,0.2,0.3,0.4$, 0.5 and 0.6 seconds.
Table 1. Simulated Cases; Refer to Figure 2.

\begin{tabular}{|c|c|c|c|}
\hline Case & Fault No & Bus No & Bus Voltage /[kV] \\
\hline 1 & F-0_1 & B-0 & 132 \\
\hline 2 & F-3_1 & B-3_2 & 132 \\
\hline 3 & F-4_1 & B-4_7 & 132 \\
\hline 4 & F-5_1 & B-5_4 & 66 \\
\hline
\end{tabular}

\section{Simulation Results and Discussion}

FRT performance for four different cases as described in Table 1 is provided in Figure 3.

According to the results given in Figure 3, the available generation after a fault decreases with the increase in fault duration time for the cases 1,2 and 4. This observation shows that the short circuit impacts to the generators increase when the fault duration time is increased. Case 1 out of four cases is selected at the main $132 \mathrm{kV}$ bus (B-0) of the Figure 2, where the impact to the system stability is high. For the Case1, the voltage at the bus B-0 is reduced to a very low value (not 0 , because of external fault to the bus) and according to the equation (3), power delivering ability decreases. Simultaneously, the electrical torque is reduced and acceleration torque is increased according to the equation (2). When the electrical power output suddenly get reduced, the delta angle of the machine is increased considerably as explained in equation (1). Case 1 condition is the worst case condition for the system 
stability. Further, the cases 2, 3 and 4 show that more than 89 percent of the generating capacity stays in synchronism when the fault duration time is less than 0.20 seconds.

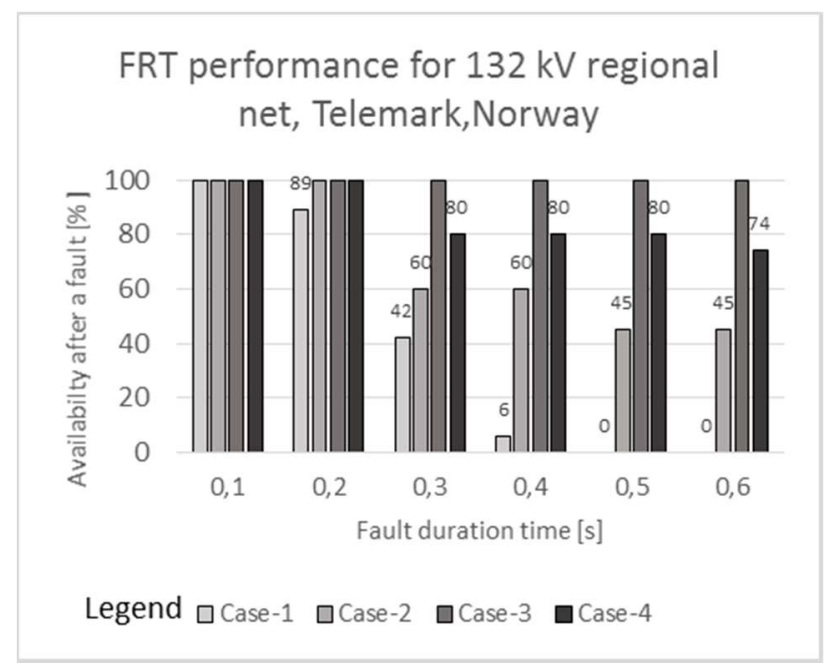

Figure 3. FRT performance of the generators for four different cases referred to Table 1, when a three-phase symmetric fault is executed. Generation capacity of the region is $418 \mathrm{MW}$.

Figure 4 shows the generator speed response of five generators, which are located in Figure 2 for the cases 1 and 3. For both cases, speed of the generators get stabilized. Figure 5 shows that the voltage of the same generators get stabilized for cases 1 and 3 .

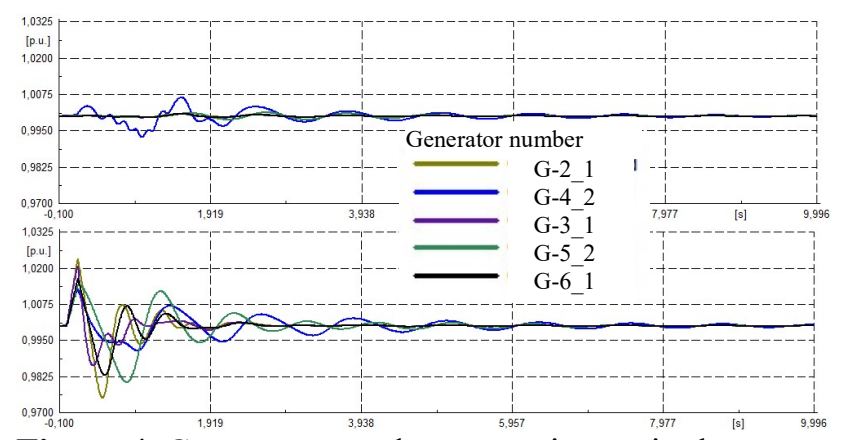

Figure 4. Generator speed response in p.u. in the event of $0.15 \mathrm{~s}$ three-phase fault: upper plot for the Case 3 and lower plot for the Case 1.

With respect to frequency stability of the Norwegian power system, the total system should withstand any single fault included loss of the biggest operating unit, which is a nuclear unit connected to Nordic network producing $1400 \mathrm{MW}$. The maximum stationary frequency deviation should be kept within $0.5 \mathrm{~Hz}$ (Statnett, 2017).

In a regional transmission system, the installed capacity is far less than $1400 \mathrm{MW}$ and if the system remains interconnected during a fault as described above, the prospected system frequency deviation is negligible.
Frequency stability of the separated system (Islanded mode) is not discussed here.

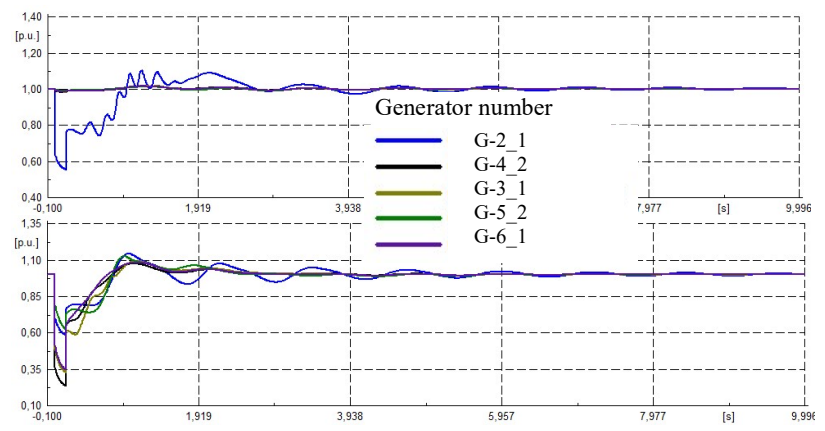

Figure 5. Generator voltage response in p.u. in the event of $0.15 \mathrm{~s}$ three-phase fault: upper plot for the Case 3 and lower plot for the Case 1.

\section{Conclusion}

The simulation results show that the structure of the Nordic power system has positive effects to the system stability. About 80 percent of the $132 \mathrm{kV}$ generating capacity of the model stayed in synchronism for the fault clearance time between $0.25-0.3 \mathrm{~s}$. If the upper time limit is reduced to $0.25 \mathrm{~s}$, it positively affects to the construction of generating stations mainly by reducing the inertia of generating stations. The results encourage to analyze the topic further.

According to the simulation results, a fault generally gives significant impacts to the nearby generating stations. As many of the hydropower stations in Norway are located in a distributed network, the improvements in relay systems would be a better solution for the upper limit of the FRT requirement which is required by the Norwegian network code.

\section{References}

Adb AH. Transient stability and Fault Ride Through (FRT) Capability of Hydropower units in Norwegian regional power networks: University College of Southeast Norway; 2016.

Bekele G, Abdela A. Investigation of Wind Farm Interaction with Ethiopian Electric Power Corporation's Grid. Energy Procedia. 2012; 14:8. doi: 10.1016/j.egypro.2011.12.1165

Delfanti M, Falabretti d, Merlo M, Monfredini G. Distributed Generation Integration in the Electric Grid: Energy Storage System for Frequency Control. Journal of Applied Mathematics. 2014; 2014:13. doi: 10.1155/2014/198427

Diez-Maroto L, Rouco L, Fernandez-Bernal F. Fault ride through capability of round rotor synchronous generators: Review, analysis and discussion of European grid code requirements. Electric Power Systems Research. 2016;140:10. doi: 10.1016/j.epsr.2016.06.046

ENTSO-e. European network of transmission system operators for electricity, available at www.entsoe.eu, 2017 
FIKS. Funksjonskrav i Kraftsystemet / Functional requirements in the Norwegian power system. Tech. rep. available at www.statnett.no, 2012

Gebremedhin A.,Granheim J.D.O. Is there a space for additional renewable energy in the Norwegian power system? Potential for reduced global emission? Renewable and Sustainable Energy Reviews, 2012. doi: 10.1016/j.rser.2011.11.032

Kundur P. Power System Stability and Control: McGrow-Hill; 1993.

Kundur P, Paserba J, Ajjarapu V, Andersson G, Bose A, Canizares $\mathrm{C}$, et al. Definition and Classification of Power System Stability. IEEE TRANSACTIONS ON POWER SYSTEMS. 2004;19(2):15.

Statnett, the system operator in the Norwegian energy System. Available at www.statnett.no, 2017

Vaahedi E. Practical Power System Operation: John Wiley \& Sons; 2014.

Weedy BM, Cory BJ, Jenkins N, Ekanayake JB, Strbac G. Electric Power Systems. 5 ed: John Wiley \& Sons Ltd; 2012. 